

\title{
Influência da Temperatura Interpasse nas Propriedades do Aço Inoxidável Duplex Durante a Soldagem pelo Processo a Arco Submerso
}

\author{
(Influence of Interpass Temperature on the Properties of Duplex Stainless Steel During Welding by Submerged Arc Welding \\ Process)
}

\author{
Tatiana Resende Alvarez ${ }^{1}$, Marjorie Rosemback Correia Pavarino ${ }^{1}$, Guttemberg Chagas de Souza ${ }^{1}$, Juan Manuel Pardal ${ }^{1}$, Sérgio \\ Souto Maior Tavares ${ }^{1}$, Miguel Luiz Ribeiro Ferreira ${ }^{1}$ e Ismael Cardote Filho ${ }^{2}$ \\ ${ }^{1} U F F$ - Universidade Federal Fluminense/Departamento de Engenharia Mecânica / PGMEC / Pós-graduação em Montagem \\ Industrial-Niterói-RJ, Brasil-juanpardal@vm.uff.br \\ ${ }^{2}$ UTC Engenharia, Niterói - RJ, Brasil
}

\section{Resumo}

Os aços inoxidáveis duplex (AID) são materiais que apresentam elevada resistência à corrosão com altos valores de resistência mecânica motivando sua utilização em diversos componentes de processo na indústria offshore. No entanto, existem grandes desafios na soldagem destes materiais em termos de produtividade e qualidade da junta produzida, tendo em vista sua ampla utilização desde componentes de pequenas espessuras, tais como umbilicais, até de grandes espessuras, como tubulações de linhas de injeção de água salgada. No que concerne a tubulações de espessuras pequenas é empregado satisfatoriamente o processo de soldagem Gas Tungsten Arc Welding (GTAW) conhecido como TIG. No que diz a respeito a tubulações de paredes espessas foi implementado, recentemente, o processo automático de soldagem por arco submerso (SAW) na linha de pré-montagem de tubulações, aumentando consideravelmente a produtividade das juntas produzidas. No entanto, existe uma grande demanda de tempo para a realização de um novo passe de solda, em virtude da máxima temperatura interpasse exigida ser inferior a $150^{\circ} \mathrm{C}$. Portanto, o presente trabalho apresenta os resultados da caracterização e avaliação da resistência à corrosão de uma junta soldada correspondente a uma tubulação de aço inoxidável duplex (AID) UNS S31803 de 21,4 mm de espessura de parede soldada pelos processos de soldagem MIG (GMAW) na raiz e arco submerso (SAW) no enchimento e acabamento, empregando-se temperaturas interpasses entre 150 e $290^{\circ} \mathrm{C}$. Os resultados da caracterização das propriedades mecânicas, composição química e resistência à corrosão em diversas regiões da junta soldada foram comparadas com os obtidos para o metal de base (MB) da tubulação, assim como com os valores mínimos exigidos pelas normas de projeto. Deste modo, o presente trabalho permite avaliar a influência da temperatura interpasse nas propriedades da junta em decorrência de um possível aumento da produtividade durante a soldagem.

Palavras-chave: Aços Inoxidáveis Duplex; Soldagem a Arco Submerso; Temperatura Interpasse; Propriedades Mecânicas; Resistência à Corrosão.

Abstract: Duplex stainless steels (DSS) are materials that present high corrosion resistance with high values of mechanical strength, therefore motivating their use in various components in the offshore industry. However, there are major challenges in the welding of these materials in terms of the productivity and quality of the joint produced, considering its extensive use for components of small thickness, such as umbilicals, to those of large thickness, such as salt water injection pipe lines. In relation to pipes of small thickness, the gas tungsten arc welding process (GTAW) is successfully used. In thick-walled pipes the automatic process of submerged arc welding (SAW) has been recently implemented in lines of pre-assembled piping, and this has considerably increased the productivity of the joints produced. Though, a great deal of time is required to perform a new weld pass, due to the fact that the maximum interpass temperature needs to be lower than $150^{\circ} \mathrm{C}$. This work presents the results of characterization and the evaluation of corrosion resistance of a welded joint corresponding to DSS UNS S31803, with a wall thickness of $21.4 \mathrm{~mm}$, welded by the gas metal arc welding process (GMAW), in the root, and submerged arc welding process $(S A W)$, in the filling and cap passes, employing an interpass temperature between 150 and $290^{\circ} \mathrm{C}$. The results of the characterization of the mechanical properties, chemical composition and corrosion resistance in different regions of the welded joint were compared with those obtained for the base metal of the pipe, as well as, with the minimum values required by the project standards. Therefore, this study has made an evaluation of the influence of the interpass temperature in the properties of the joints produced, motivated by a possible increase of productivity in pipe welding.

Key-words: Duplex Stainless Steels; Submerged Arc Welding; Interpass Temperature; Mechanical Properties; Corrosion Resistance.

Recebido em 07/03/2014, texto final em 23/04/2014.

DOI: $10.1590 / 0104-9224 / S I 1902.03$ 


\section{Introdução}

Os aços inoxidáveis duplex (AID) são ligas ferrosas contendo proporções similares de fases austenita e ferrita. Estas ligas são extensamente utilizadas principalmente em indústrias offshore, produto da elevada resistência mecânica com altos valores do índice equivalente de resistência ao pite (PRE) se comparado com outras designações de aços inoxidáveis austeníticos convencionais $[1,2]$.

Um dos desafios atuais durante a soldagem destes aços se sustenta na utilização de processos que visam o aumento de produtividade, mantendo-se a proporção de austenita precipitada entre 30 e $70 \%$, além de evitar a formação de fases terciárias como chi $(\chi)$ e sigma $(\sigma)$ na microestrutura $[3,4]$.

Recentemente foi implementado em empreendimentos de construção e montagem de tubulações, na soldagem de tubulações espessas, o processo arco submerso ( $S A W$ ) nos passes de enchimento e acabamento da junta, dando lugar a um notório aumento da produtividade na pré-montagem de spools de linhas de injeção de água salgada [4]. No entanto, existe uma grande demanda de tempo para a realização de um novo passe de solda, em virtude da máxima temperatura interpasse exigida ser inferior a $150^{\circ} \mathrm{C}$. Este valor é limitado afim de não produzir um baixo valor da velocidade de resfriamento que conduza a um elevado teor de austenita precipitada podendo ainda conter fases deletérias chi $(\chi)$ e sigma $(\sigma)$, causando a queda da resistência à corrosão e da tenacidade ao impacto. Por este motivo, é importante, na soldagem destas ligas, controlar a velocidade de resfriamento mediante o aporte de calor ou energia de soldagem e a temperatura interpasse, sendo estes parâmetros determinantes para um correto balanço microestrutural em juntas soldadas de AID. Neste sentido, o aporte térmico costuma ser controlado na faixa de $0,5 \mathrm{~kJ} / \mathrm{mm}$ a $2,5 \mathrm{~kJ} / \mathrm{mm}$ para o caso do AID 2205 [5].

Portanto, o presente trabalho apresenta os resultados da caracterização e avaliação da resistência à corrosão de uma junta soldada correspondente a uma tubulação de aço inoxidável duplex
(AID) UNS S31803 de 21,4 mm de espessura de parede, soldada pelos processos de soldagem MIG $(G M A W)$, na raiz, e arco submerso $(S A W)$, no enchimento e acabamento, empregando-se temperaturas interpasses entre 150 e $290^{\circ} \mathrm{C}$. A soldagem pelo processo $S A W$ teve como particularidade o uso de uma fonte de corrente alternada com onda quadrada (CA) que permitiu uma maior taxa de deposição e uma consequente realização da junta em um menor número de passes se comparado com o trabalho recentemente reportado pela nossa equipe [4].

Os resultados da caracterização da tenacidade ao impacto, microestrutura, teor de nitrogênio e resistência à corrosão em diversas regiões da junta soldada foram comparadas com os obtidos para o metal de base (MB) da tubulação, assim como com os valores mínimos exigidos pelas normas de projeto. Deste modo, o presente trabalho permite avaliar a influência da temperatura interpasse nas propriedades da junta em decorrência de um possível aumento da produtividade durante a soldagem.

\section{Materiais e Métodos}

O material da tubulação é uma liga correspondente à designação UNS S31803, fabricada conforme a norma ASTM A 928 classe 1 , na forma de um tubo com costura, de $273,1 \mathrm{~mm}$ de diâmetro e 21,4 mm de espessura de parede, fornecido no estado solubilizado. Na Tabela 1 são apresentadas as composições químicas do material de base e dos consumíveis empregados para soldagem, que correspondem à classificação de aços inoxidáveis duplex.

Os arames utilizados foram da marca comercial SANDVIK 22.8.3L conforme AWS ER 2209, com diâmetros de 1,2 e 2,4 mm para os processos $G M A W$ e $S A W$, respectivamente. Na soldagem pelo processo $S A W$ foi utilizado fluxo básico SANDVIK $15 \mathrm{~W}$ com índice de basicidade igual a 1,9 de acordo com informações fornecidas pelo fabricante.

A geometria e dimensões do bisel empregado são apresentadas na Figura 1 (a), onde a abertura da junta utilizada

Tabela 1. Composição química dos materiais utilizados.

\begin{tabular}{|c|c|c|c|c|c|c|c|c|c|c|c|}
\hline \multirow{2}{*}{ Material/Arame } & \multirow{2}{*}{ Classificação } & \multicolumn{8}{|c|}{ Composição química (\% em peso) (Fe) balanço. } \\
\cline { 3 - 11 } & & Cr & Ni & Mo & Mn & Si & N & Cu & C & P & S \\
\hline Tubo & UNS S31803 & 22,889 & 5,334 & 2,837 & 1,825 & 0,320 & 0,162 & - & 0,015 & 0,029 & 0,004 \\
\hline GMAW & ER 2209 & 22,810 & 8,730 & 3,150 & 1,840 & 0,420 & 0,150 & 0,120 & 0,016 & 0,018 & 0,001 \\
\hline SAW & ER 2209 & 22,940 & 8,630 & 3,070 & 1,540 & 0,480 & 0,150 & 0,140 & 0,008 & 0,017 & 0,001 \\
\hline
\end{tabular}

a)

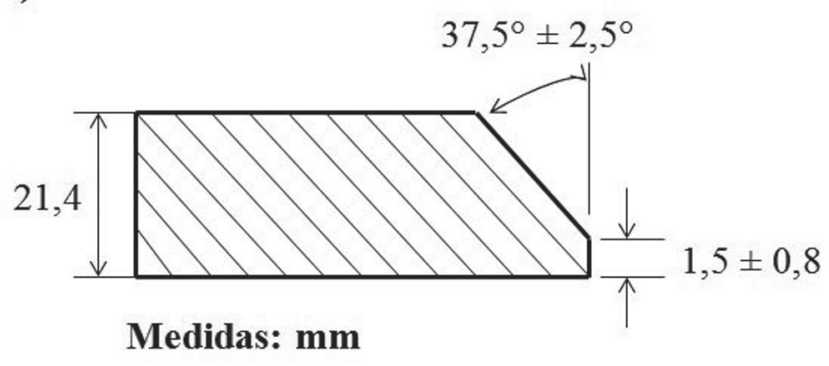

b)

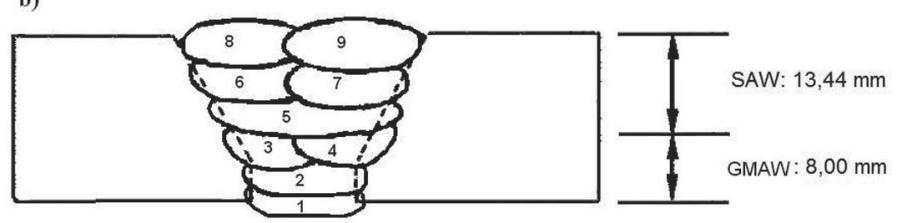

Figura 1. (a) Características do bisel do tubo de AID [6]. (b) Esquema da junta após a soldagem. 
foi de 5,0 $\mathrm{mm}$. Os processos de soldagem realizados foram MIG na raiz e seu reforço, assim como SAW no enchimento e acabamento, conforme mostrado no desenho esquemático da Figura 1 (b).

$\mathrm{O}$ gás de proteção empregado no processo $G M A W$ foi uma mistura contendo $98 \%$ argônio (Ar) $+2 \%$ oxigênio $\left(\mathrm{O}_{2}\right)$ e a purga foi realizada com um gás contendo $100 \%$ nitrogênio $\left(\mathrm{N}_{2}\right)$, com vazões de 15 e 20 litros/minuto, respectivamente. A proteção na purga foi avaliada mediante medição do teor de oxigênio no interior da tubulação com o uso de oxímetro marca Raytek, modelo Raynger MX, verificando-se o teor de oxigênio para não exceder $0,5 \%$ em peso.

A Tabela 2 exibe os diversos valores dos parâmetros dos processos de soldagens empregados, assim como a temperatura interpasse (Ti) durante a soldagem da tubulação. Foram adotados os rendimentos térmicos dos processos de soldagem iguais a 1 , de forma que o controle da energia de soldagem seja mais conservador.

Conforme mostrado na Tabela 2, a polaridade empregada foi corrente contínua inversa $(\mathrm{CC}+)$ para o processo $G M A W$. No primeiro passe da raiz foi empregado o processo de transferência por curto-circuito controlado, denominado STT, mediante o uso de uma fonte Lincoln Power Wave S350. Os demais passes da raiz foram feitos com transferência pulsada, onde o valor da corrente é o valor de corrente integrada. Para o processo $S A W$, a polaridade empregada foi corrente contínua inversa $(\mathrm{CC}+) \mathrm{e}$ corrente alternada (CA) de onda quadrada (SW), utilizandose a fonte Lincoln Power Wave AC/DC 1000 SD. Durante as soldagens efetuadas, a distância do bico de contacto à peça (DBCP) foi de $12 \mathrm{~mm}$ e $20 \mathrm{~mm}$ para os processos $G M A W$ e $S A W$, respectivamente. A medição da temperatura interpasse foi realizada por meio do termômetro digital de contato Icel Gubinteck TD 910D.
Esta junta foi executada com um menor número de passes se comparada em forma relativa à junta soldada de AID realizada recentemente pela nossa equipe pelo processo SAW com polaridade $\mathrm{CC}+[4]$. Este fato é atribuído principalmente à utilização de corrente alternada mediante uso da fonte inversora Power Wave, modelo AC/DC 1000SD especialmente projetada pela Lincoln para soldagem de AID e aços inoxidáveis superduplex (AISD). A utilização de corrente alternada com formato de onda quadrada (SW) proporciona um maior balanceamento na transferência de calor durante o processo, podendo deste modo, operar fundamentalmente com maiores valores de corrente de soldagem decorrendo em uma elevada taxa de transferência do metal depositado e, porém, em uma maior velocidade de alimentação de arame (Vaa). O formato da onda quadrada é ajustado no programa da fonte de soldagem através de dois valores denominados de off-set e balanço de onda. O off-set é o valor percentual de deslocamento da intensidade de corrente em relação ao valor médio desta. Por outro lado, o valor percentual do balanço de onda é aquele correspondente ao tempo de permanência da onda em cada período afetando no valor de frequência adotado. Deste modo, o valor de energia de soldagem será menor do que aquele obtido convencionalmente. Os valores de frequência, off-set e balanço de onda empregados, assim como a taxa de deposição na soldagem desta junta são mostrados na Tabela 3.

Para a realização do ensaio de impacto foi utilizado um pêndulo universal Charpy. Todos os ensaios foram realizados à temperatura de $-46^{\circ} \mathrm{C}$. Foram ensaiados 24 corpos de prova (cps) de tamanho padronizado, $55 \times 10 \times 10 \mathrm{~mm}$, com entalhe tipo "V" conforme norma ASTM E23-05 [7]. Os cps foram retirados transversalmente à junta soldada a 2,0 $\mathrm{mm}$ da superfície da raiz e do enchimento, como indicado na Figura 2 (a). O entalhe, tal como apresentado esquematicamente na Figura 2 (a-b), foi

Tabela 2. Valores das variáveis do processo de soldagem para cada passe efetuado.

\begin{tabular}{|c|c|c|c|c|c|c|c|c|}
\hline Passe $\mathbf{N}^{o}$ & Camada $\mathbf{N}^{\circ}$ & Processo & $\begin{array}{c}\text { Tensão } \\
\text { média (V) }\end{array}$ & $\begin{array}{c}\text { Corrente de } \\
\text { Soldagem (A) }\end{array}$ & $\begin{array}{l}\text { Velocidade } \\
\text { (cm/min) }\end{array}$ & $\begin{array}{c}\text { Vaa } \\
(\mathrm{mm} / \mathrm{s})\end{array}$ & $\begin{array}{c}\text { Energia de } \\
\text { Soldagem }(\mathrm{kJ} / \mathrm{mm})\end{array}$ & $\begin{array}{c}\mathrm{Ti} \\
\left({ }^{\circ} \mathrm{C}\right)\end{array}$ \\
\hline 1 & 1 & \multirow{4}{*}{ GMAW (CC+) } & 15 & 110 & 10,00 & 63,50 & 0,99 & 26 \\
\hline 2 & 2 & & 13 & 120 & 13,00 & 67,73 & 0,72 & 86 \\
\hline 3 & \multirow{2}{*}{3} & & 13 & 120 & 13,00 & 67,73 & 0,72 & 101 \\
\hline 4 & & & 13 & 120 & 13,00 & 67,73 & 0,72 & 105 \\
\hline 5 & 4 & SAW $(C C+)$ & 30 & 300 & 41,41 & 38,95 & 1,30 & 33 \\
\hline 6 & \multirow{2}{*}{5} & \multirow{4}{*}{ SAW (CA SW) } & 30 & 300 & 48,21 & 50,80 & 1,12 & 160 \\
\hline 7 & & & 30 & 430 & 48,38 & 76,20 & 1,60 & 240 \\
\hline 8 & \multirow{2}{*}{6} & & 30 & 335 & 45,48 & 55,88 & 1,33 & 240 \\
\hline 9 & & & 30 & 400 & 45,00 & 76,20 & 1,60 & 290 \\
\hline
\end{tabular}

Tabela 3. Valores da frequência, off-set e balanço de onda empregados, assim como a taxa de deposição para cada passe.

\begin{tabular}{|c|c|c|c|c|c|c|}
\hline $\operatorname{Passe} \mathrm{N}^{\mathrm{o}}$ & Camada $\mathbf{N}^{\circ}$ & Processo & Frequência $(\mathrm{Hz})$ & Off-set $(\%)$ & Balanço de onda (\%) & Taxa de Deposição $(\mathrm{kg} / \mathrm{h})$ \\
\hline 6 & \multirow{2}{*}{5} & \multirow{4}{*}{$\begin{array}{c}\text { SAW } \\
\text { (CA SW) }\end{array}$} & 60 & -15 & +30 & 6,30 \\
\hline 7 & & & 80 & -25 & +25 & 9,50 \\
\hline 8 & \multirow{2}{*}{6} & & 60 & -15 & +40 & 7,02 \\
\hline 9 & & & 80 & -25 & +25 & 9,57 \\
\hline
\end{tabular}


realizado no centro do metal de solda (CS), na zona de ligação ou linha de fusão (LF) e a 2,0 e 5,0mm da LF na direção da ZTA, totalizando 3 corpos de prova em cada condição, tal como especificado pela norma SBM SPF92033A1 [8].

Foi efetuada uma análise macrográfica da junta soldada, preparada através de lixamento convencional até lixa de granulometria 400, com posterior ataque eletrolítico através de solução aquosa de ácido oxálico a $10 \%$ com aplicação $3 \mathrm{~V}$ durante 3 minutos com a amostra fixada no anodo. A caracterização foi realizada mediante uso de um microscópio estéreo convencional.

Para as análises metalográficas e da resistência à corrosão foram retiradas cinco amostras da tubulação soldada, duas na raiz, uma no metal de base (MB), uma no centro do enchimento do metal de solda (MS) e uma no acabamento, nas posições indicadas na Figura 3. As coordenadas aproximadas, das amostras extraídas de acordo com a Figura 3, são exibidas na Tabela 4. Cabe ressaltar que, para determinação precisa dos locais analisados da junta, foi efetuada prévia ao corte, uma macrografia com procedimento semelhante ao comentado no parágrafo anterior.

As amostras indicadas foram caracterizadas em um microscópio óptico (MO) pelo procedimento metalográfico convencional através do emprego dos diferentes ataques descritos na Tabela 5. Após a realização dos ensaios de impacto, a face lateral do cp Charpy do centro de solda na raiz (CSR) foi também caracterizada empregando a mesma metodologia. Entretanto, também foi cuidadosamente lixada e polida a face da superfície de fratura do cp mencionado. Deste modo, após aplicação dos reagentes indicados, podem ser observadas, simultaneamente, a microestrutura e a superfície de fratura de cada cp com o intuito de exibir os locais preferenciais de propagação de trincas.

As quantificações das fases ferrita $(\delta)$ e austenita $(\gamma)$, nas diferentes regiões da junta soldada, foram realizadas pelo programa Image Tools v.3.0 [10]. Esta análise foi realizada tomando como média em torno de 12 imagens por região da junta, com aumentos de 240X, 475X, 950X e 1900X.

As Figuras 4 (a) e (b) mostram um exemplo da segmentação de uma imagem para o metal de solda da condição $G M A W$ RAIZ 1, obtida por MO como mostra a micrografia da Figura 4 (a). A partir do uso do programa Image Tools v.3.0 [10] a imagem da Figura 4 (a) é tratada e posteriormente segmentada, obtendose a imagem binária, mostrada na Figura 4 (b). Finalmente, o referido programa contabiliza os píxeis de modo obter a proporção de fases presentes para esta condição.

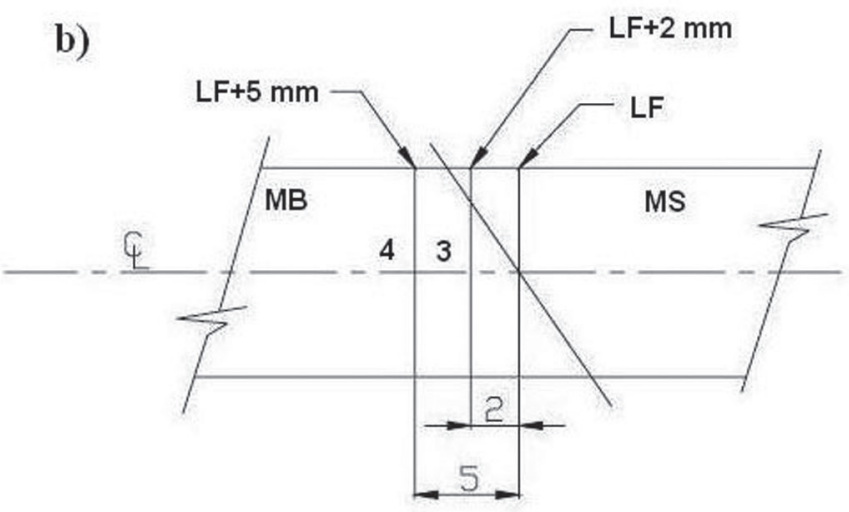

Figura 2. Localização dos cps Charpy: (a) 1 - Centro do metal de Solda (CS) e 2 - Linha de Fusão (LF). (b) 3 - LF+2,0mm e 4 $\mathrm{LF}+5,0 \mathrm{~mm}[8]$.

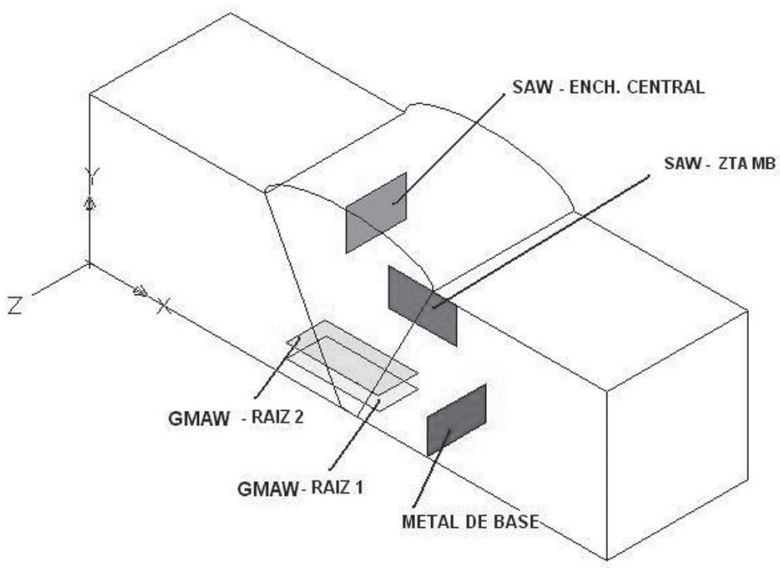

Figura 3. Esquema da locação das amostras retiradas da junta soldada. 
Tabela 4. Coordenadas das amostras extraídas de acordo com o esquema de locação da Figura 3.

\begin{tabular}{|c|c|c|}
\hline Amostra & X (mm) & Y (mm) \\
\hline GMAW - RAIZ 1 & 35 & 2 \\
\hline $\boldsymbol{G M} \boldsymbol{A} \boldsymbol{W}-$ RAIZ 2 & 35 & 5 \\
\hline SAW - ENCH. CENTRAL & 35 & 18 \\
\hline SAW - ZTA MB & 50 & 17 \\
\hline METAL DE BASE (MB) & 53 & 2 \\
\hline
\end{tabular}

Tabela 5. Reagentes utilizados para revelar características microestruturais da junta soldada [9].

\begin{tabular}{|c|c|c|}
\hline Ataque & Composição & Objetivo \\
\hline Beraha & $\begin{array}{c}\text { Solução aquecida, composta de: } 20 \mathrm{ml} \mathrm{de} \mathrm{HCl} \text { em } \\
100 \mathrm{ml} \mathrm{H}_{2} \mathrm{O} \text { destilada }+0,3 \mathrm{a} 0,6 \mathrm{~g} \text { de metabissulfito } \\
\text { de potássio. Temperatura do banho entre } 40 \text { e } 80^{\circ} \mathrm{C} .\end{array}$ & $\begin{array}{c}\text { Caracterizar as mudanças microestruturais na soldagem da } \\
\text { tubulação. Revelar as fases ferrita }(\delta) \text { e austenita }(\gamma) \text { das } \\
\text { diversas regiões da junta. }\end{array}$ \\
$\begin{array}{c}\text { KOH } \\
\text { Modificado }\end{array}$ & $\begin{array}{c}5 \mathrm{~g} \text { de } \mathrm{KOH} \text { em } 100 \mathrm{ml} \mathrm{de} \mathrm{H}_{2} \mathrm{O} \text { destilada. Ataque } \\
\text { eletrolítico: Amostra no anodo, aplicação de } 3 \mathrm{~V} \\
\text { durante } 12 \mathrm{~s} .\end{array}$ & $\begin{array}{c}\text { Caracterizar as mudanças microestruturais na soldagem da } \\
\text { tubulação. Revelar fases deletérias. }\end{array}$ \\
\hline
\end{tabular}

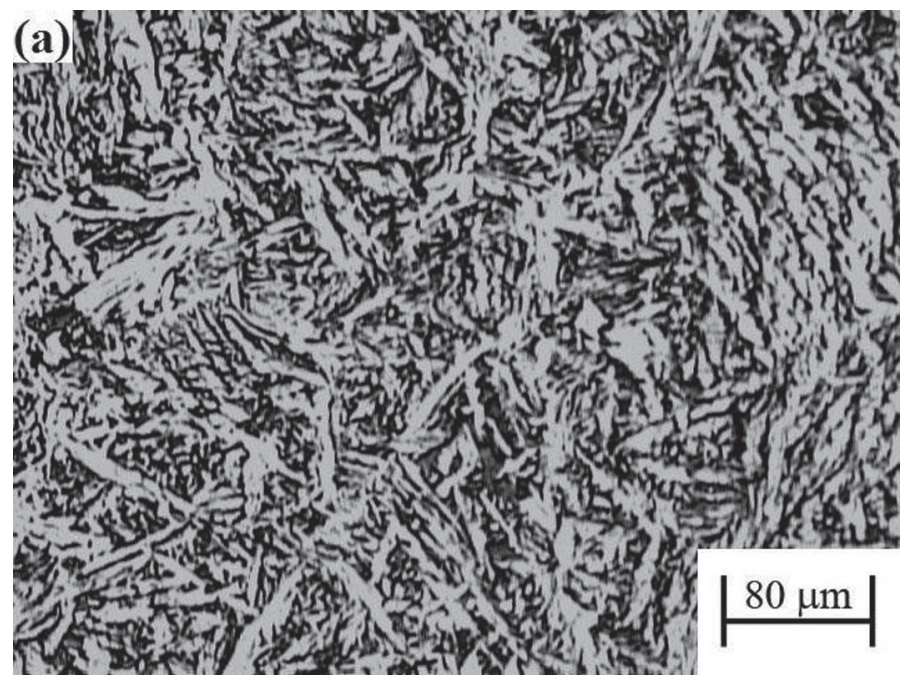

Figura 4. (a) Imagem obtida por MO do metal de solda $G M A W$

O teor de nitrogênio foi avaliado por combustão através da retirada de $1 \mathrm{~g}$ de cavaco, no metal de base (MB), na raiz (GMAW - RAIZ), na região central do metal de solda ( $S A W$ - ENCH. CENTRAL) e na região do metal solda próxima do acabamento (SAW - ACAB).

As análises eletroquímicas por estimativa da temperatura crítica de pites $(C P T)$ de cada região da junta soldada foram efetuadas se baseando na utilização da norma ASTM G150 [11]. Para realização dos ensaios foram utilizados um computador, um termômetro digital, um potenciostato galvanostato $\mu$ Autolab ${ }^{\circledR}$ Type III e uma célula eletroquímica, em banho-maria, contendo um eletrodo de trabalho a ser ensaiado, um becker com uma solução de $1 \mathrm{M} \mathrm{NaCl}$ sem desaeração prévia, um contra eletrodo de platina e um eletrodo de referência de calomelano saturado.

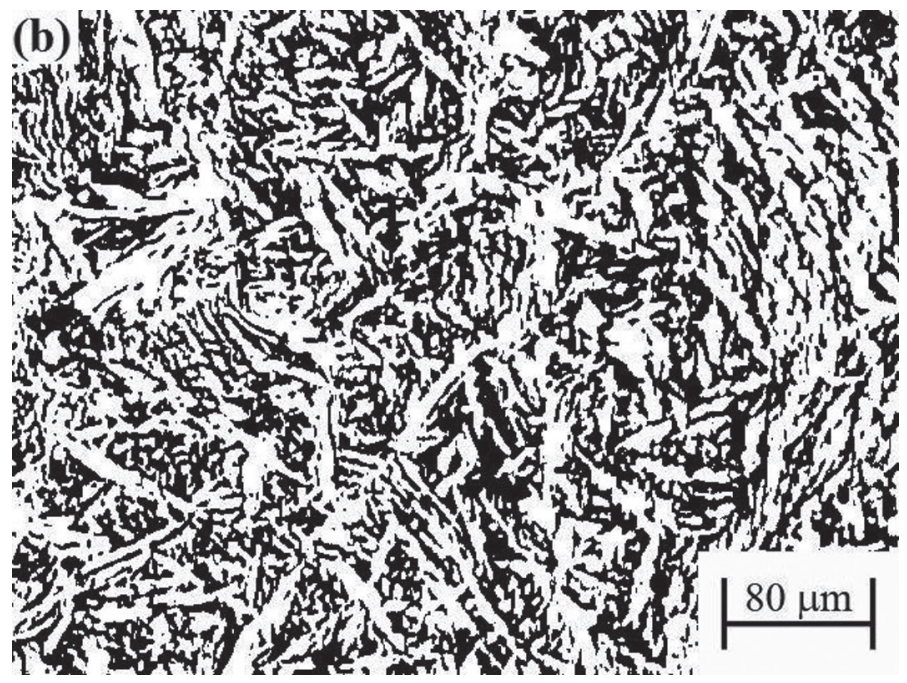

(b) Imagem binária obtida pelo programa Image Tools v.3.0 [10].

A fabricação dos eletrodos de trabalho foi realizada por fixação de fios rígidos de cobre $(\mathrm{Cu})$ nas 5 amostras extraídas das distintas regiões da junta soldada conforme mostrado na Figura 3. Os eletrodos foram embutidos em resina de cura a frio. A superfície de cada amostra em contato com o eletrólito foi preparada até a lixa com granulometria 400 e as laterais e vértices do eletrodo em contato com a resina foram recobertas por esmalte incolor com o intuito de evitar corrosão por frestas na amostra. Durante o ensaio, um potencial constante de $700 \mathrm{mV}_{\mathrm{SCE}}$ foi aplicado na amostra em relação ao eletrodo de referência de calomelano saturado $(S C E)$. Os valores de temperatura foram adquiridos manualmente em intervalos de quinze segundos, utilizando um termômetro digital. $\mathrm{O}$ aquecimento da solução foi realizado com uma taxa de aproximadamente $4^{\circ} \mathrm{C}$ por minuto, a 
partir da temperatura de $9^{\circ} \mathrm{C}$.

No computador conectado a célula eletroquímica e ao potenciostato, foram representados, graficamente, os valores de temperatura e densidade de corrente versus o tempo de ensaio. Assim, a $C P T$ é a temperatura pela qual a densidade de corrente

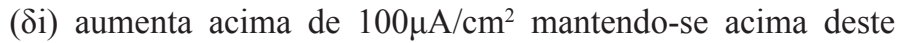
valor crítico no mínimo por sessenta segundos [11]. Seguindo a metodologia descrita foram realizados três ensaios para cada amostra avaliada e calculada uma média do valor de temperatura crítica de pites. Como exemplo, a Figura 5 exibe um dos ensaios de $C P T$ realizado na amostra $G M A W$ - RAIZ 2.

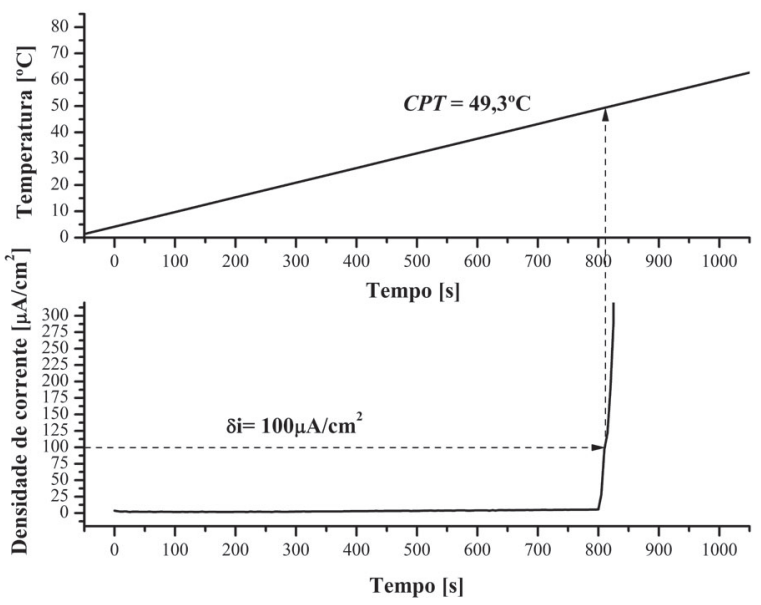

Figura 5. Determinação gráfica do $C P T$ do terceiro ensaio da condição $G M A W$ - RAIZ 2.

\section{Resultados e Discussão}

A Figura 6 apresenta a análise macrográfica da seção transversal da junta analisada denotando-se claramente cada cordão de solda depositado. Nesta análise não foi evidenciada falta de fusão e penetração do metal de solda.

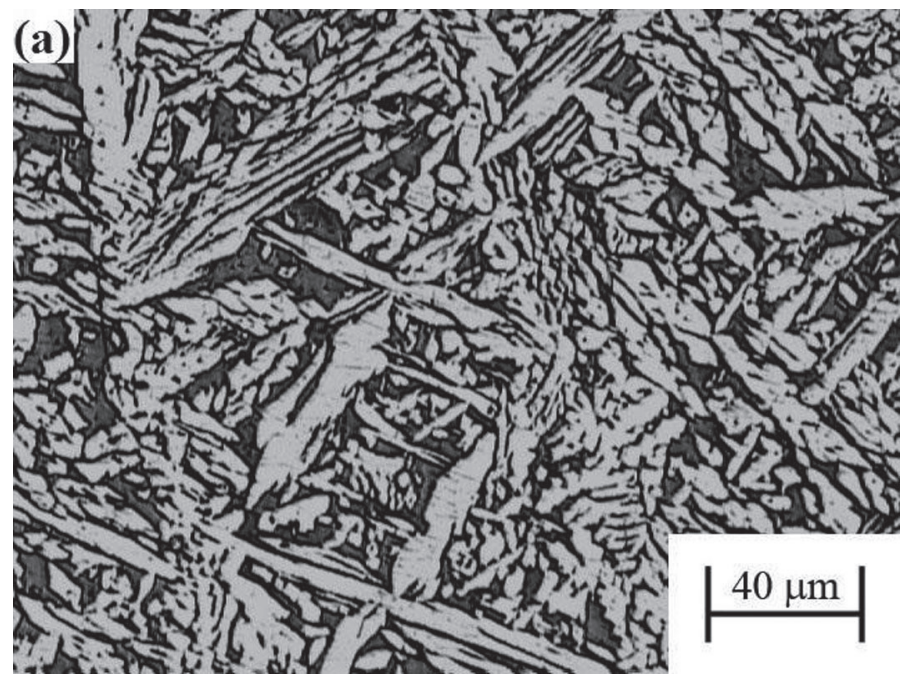

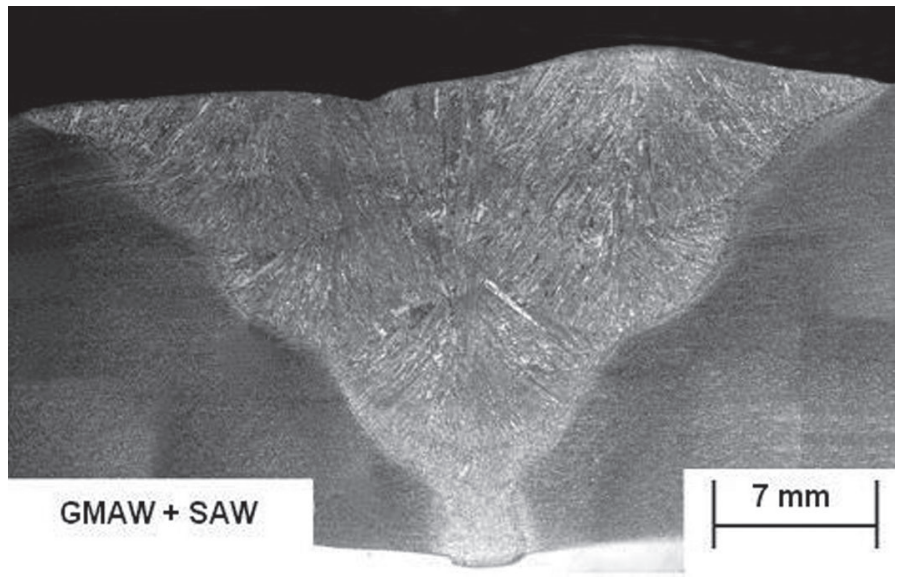

Figura 6. Macrografia da junta soldada exibindo os passes de solda depositados.

As Figuras 7 (a) e (b) exibem a microestrutura do MS nas amostras $G M A W$ - RAIZ 1 e na GMAW - RAIZ 2, respectivamente, e nas Figuras 8 (a) e (b) se observa claramente a zona de ligação mostrando a ZTA destas regiões da junta. Nas Figuras 8 (a) e (b) se evidencia claramente o forte efeito de refino microestrutural das fases precipitadas em relação à ZTA e o MB. Salienta-se, ainda, que não foram observados defeitos na linha de fusão (LF) em ambas as regiões. A proporção da ferrita (fase escura) do MS das amostras GMAW - RAIZ 1 e $G M A W$ - RAIZ 2 foram de $49,94 \pm 2,41 \%$ e $46,67 \pm 1,72 \%$, respectivamente. $\mathrm{Na}$ região da ZTA a proporção de ferrita $(\delta)$ foi de $61,02 \pm 1,95 \%$ e $55,29 \pm 2,13 \%$ para $G M A W$ - RAIZ 1 e a $G M A W$ - RAIZ 2, respectivamente. Salienta-se que todos os valores se encontram dentro do escopo da norma NORSOK M-601 [3]. Deste modo, denota-se que a influência dos sucessivos ciclos térmicos e da temperatura interpasse elevada não afetou significativamente na proporção de fases na região da raiz da solda.

A microestrutura do metal de solda (MS) na amostra $S A W$

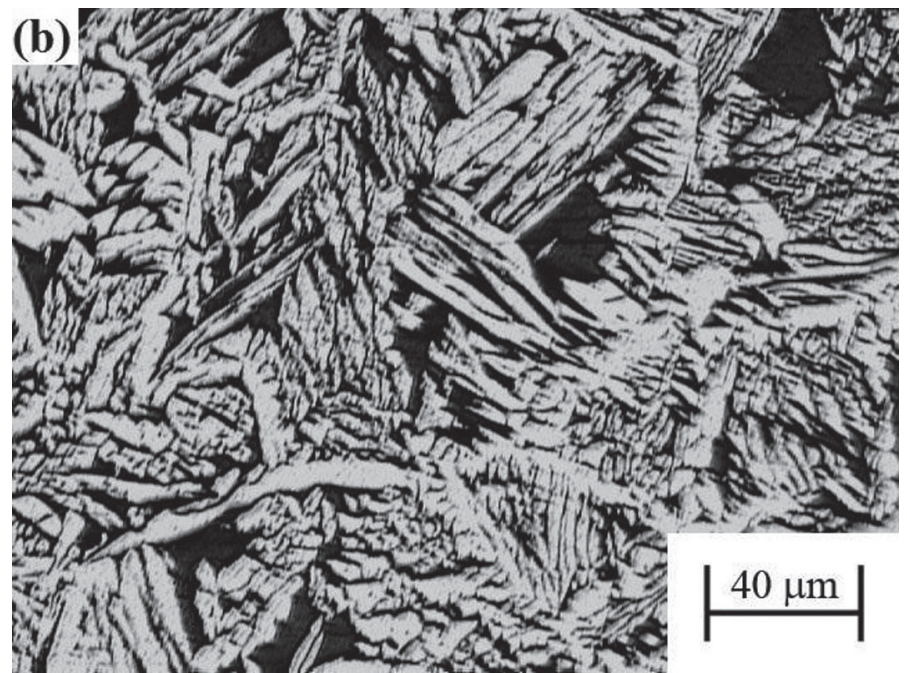

Figura 7. (a) Microestrutura do MS do GMAW - RAIZ 1. (b) Microestrutura do MS do GMAW - RAIZ 2. 

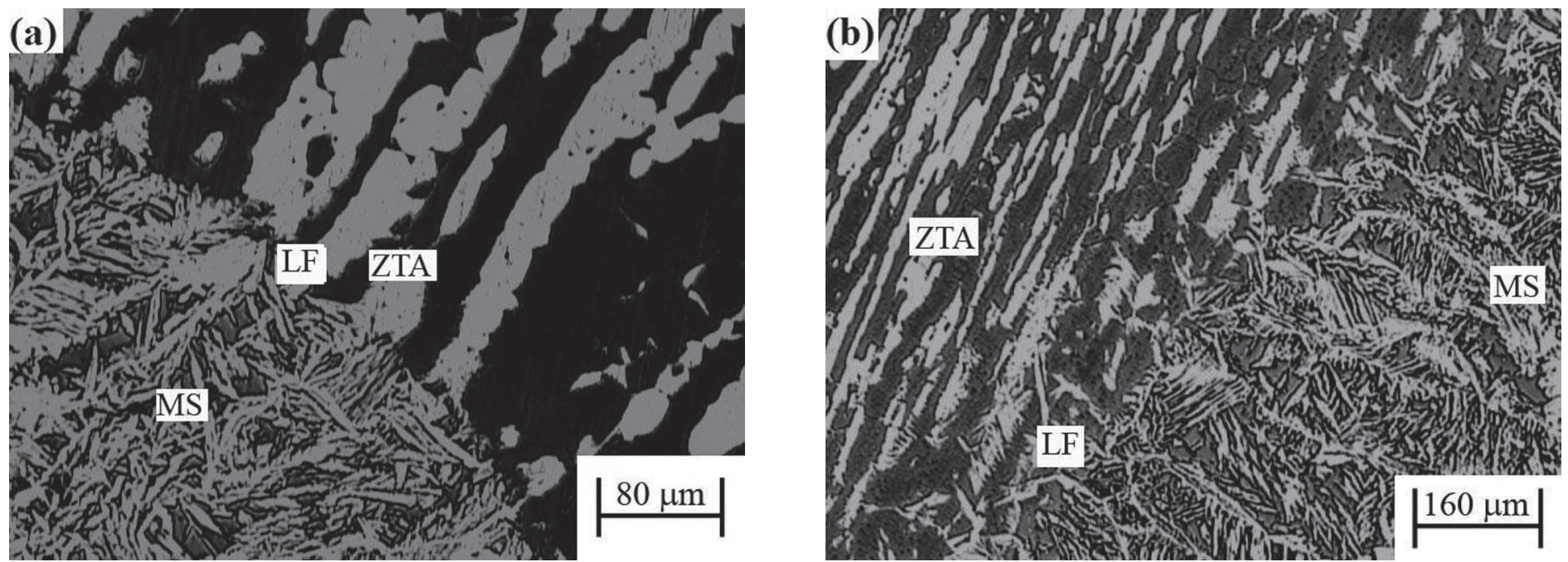

Figura 8. (a) Microestrutura da LF do GMAW - RAIZ 1. (b) Microestrutura da LF do GMAW - RAIZ 2.

- ENCH. CENTRAL é exibida na Figura 9. A proporção da fase ferrita nesta região é de $53,73 \pm 2,81 \%$, estando também de acordo com as especificações da NORSOK M-601 [3].

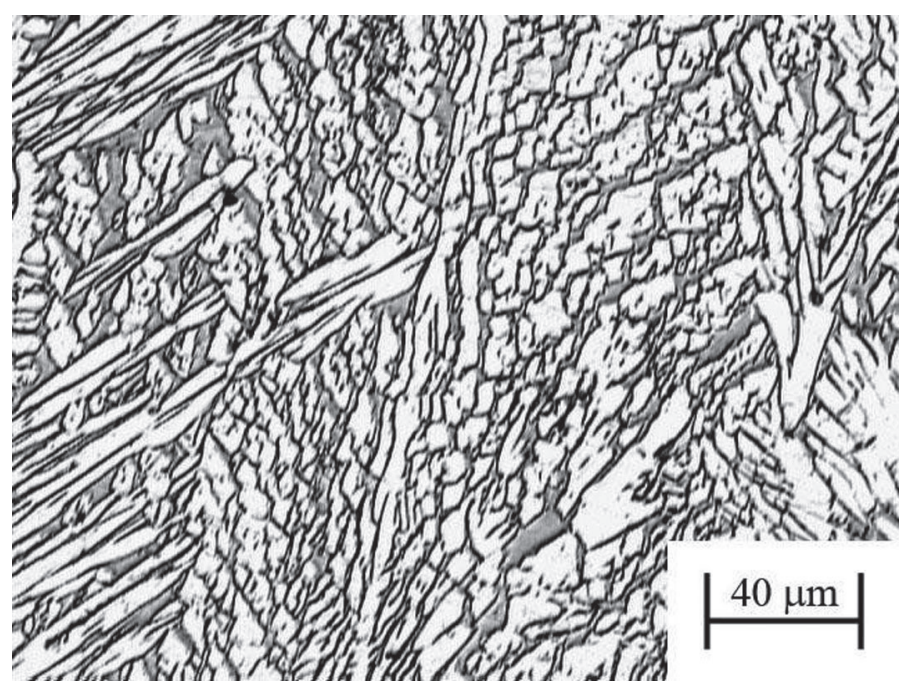

Figura 9. Microestrutura do MS do $S A W-$ ENCH. CENTRAL.
A Figura 10 mostra a linha de fusão (LF) da amostra $S A W-$ ZTA MB, detalhando a ZTA. A proporção de ferrita (fase escura) em sua microestrutura é de $61,52 \pm 2,73 \%$ na região da ZTA e de $51,62 \pm 1,79 \%$ no MS, valores que também se encontram dentro de escopo da norma (NORSOK M-601, 2004).

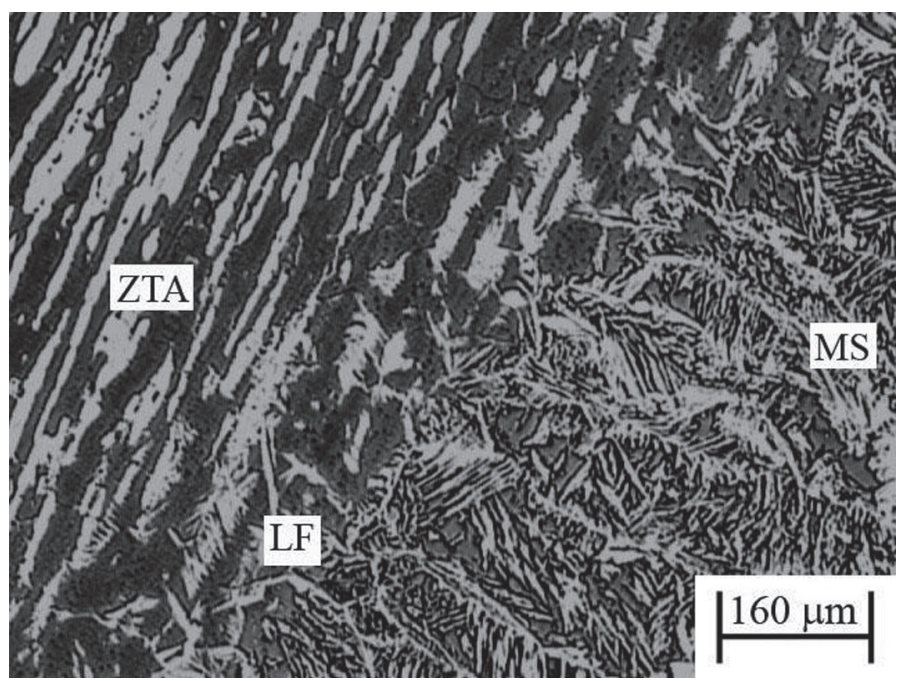

Figura 10. Microestrutura da LF do $S A W$ - ZTA MB.

Tabela 6. Percentuais médios de ferrita e austenita obtidos em diferentes regiões da junta soldada.

\begin{tabular}{|c|c|c|c|}
\hline Amostra & Região & Ferrita (\%) & Austenita (\%) \\
\hline \multirow{2}{*}{$G M A W-$ RAIZ 1} & MS & $49,94 \pm 2,41$ & $50,06 \pm 2,41$ \\
\hline & ZTA & $61,02 \pm 1,95$ & $38,98 \pm 1,95$ \\
\hline \multirow{2}{*}{$G M A W$ - RAIZ 2} & MS & $46,67 \pm 1,72$ & $53,33 \pm 1,72$ \\
\hline & ZTA & $55,29 \pm 2,13$ & $44,71 \pm 2,13$ \\
\hline$S A W$ - ENCH. CENTRAL & MS & $53,73 \pm 2,81$ & $46,27 \pm 2,81$ \\
\hline \multirow{2}{*}{$S A W$ - ZTA MB } & MS & $51,62 \pm 1,79$ & $48,38 \pm 1,79$ \\
\hline & ZTA & $61,52 \pm 2,73$ & $38,38 \pm 2,73$ \\
\hline MB & MB & $58,90 \pm 1,82$ & $41,10 \pm 1,82$ \\
\hline
\end{tabular}


A Tabela 6 apresenta os percentuais médios de ferrita e austenita encontrados nas diversas regiões da junta soldada.

Pode ser observado que o GMAW Raiz 1 - MS e o $G M A W$ Raiz 2 - MS apresentaram um percentual levemente maior de austenita (fase clara) em relação às demais regiões da junta. Em relação ao MB isso pode ser atribuído ao fato do consumível de AID possuir teores mais elevados de $\mathrm{Ni}$ (em torno de 3,4\% a mais) e proporções de $\mathrm{N}$ perto de seu limite de solubilidade, estabilizando a austenita $(\gamma)$, o que geralmente favorece as propriedades da junta [5]. Na região $S A W$ - ENCH. CENTRAL obteve-se um percentual menor de $\gamma$ com relação aos $G M A W$ Raiz 1 - MS e GMAW Raiz 2 - MS. Essa pequena diferença pode ser atribuída à influência dos ciclos de reaquecimento no MS da raiz auxiliada pela elevada temperatura interpasse nos passes de enchimento. Além disso, os teores dos principais elementos austenitizantes no arame usado no processo $S A W$, tal como Ni e Mn, são levemente inferiores ao do arame usado no processo $G M A W$, tal como mostrado na Tabela 1.

Em relação aos valores de proporção de fases obtidos na ZTA da junta, conforme observado na Tabela 6 , as proporções de ferrita estão próximas ao do MB, em todos os casos, salientandose que não houve influência da temperatura interpasse na proporção de fases nesta região.

Baseado na norma NORSOK M-601 [3], as amostras devem possuir, para aceitação, percentual entre 30\% e 70\% de ferrita. Pode-se observar que, conforme comentado, todos os percentuais encontrados e apresentados na Tabela 6 atendem à especificação, além de apresentarem valores equilibrados, especialmente na zona do MS da amostra GMAW - RAIZ 1, que costuma ser a região mais crítica da junta em virtude de sofrer ciclos sucessivos de aquecimento.

A Figura 11 apresenta o $\mathrm{MB}$ atacado pelo reagente de $\mathrm{KOH}$ modificado. Conforme observado, se distingue tenuamente a fase ferrita (escura) e austenita (clara), não existindo regiões de ataque localizado, fundamentalmente se analisado as interfaces $\delta / \gamma$. Portanto, conclui-se que o MB sob estas condições encontrase isento de fases deletérias.

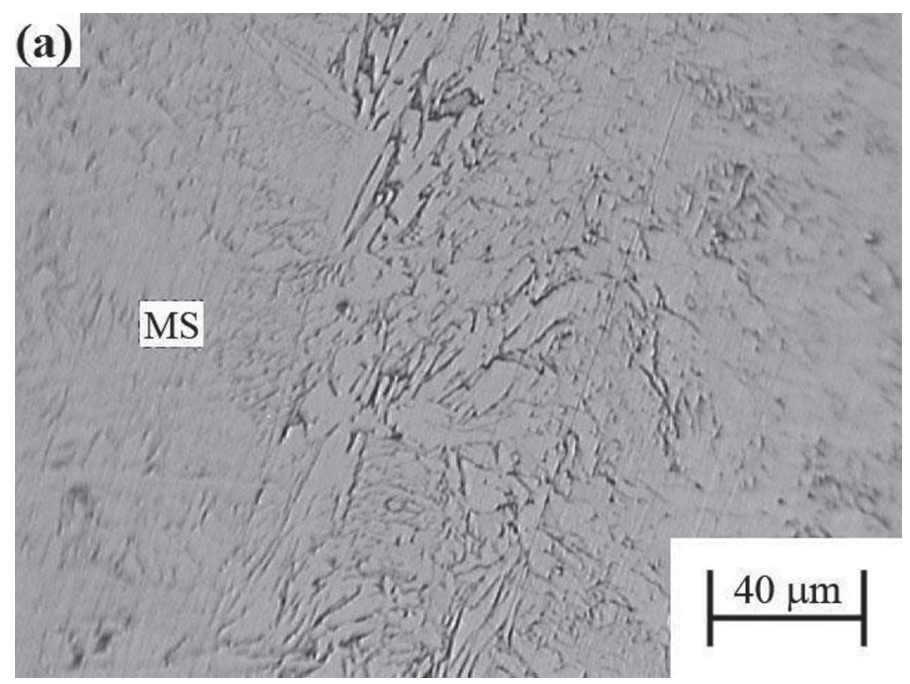

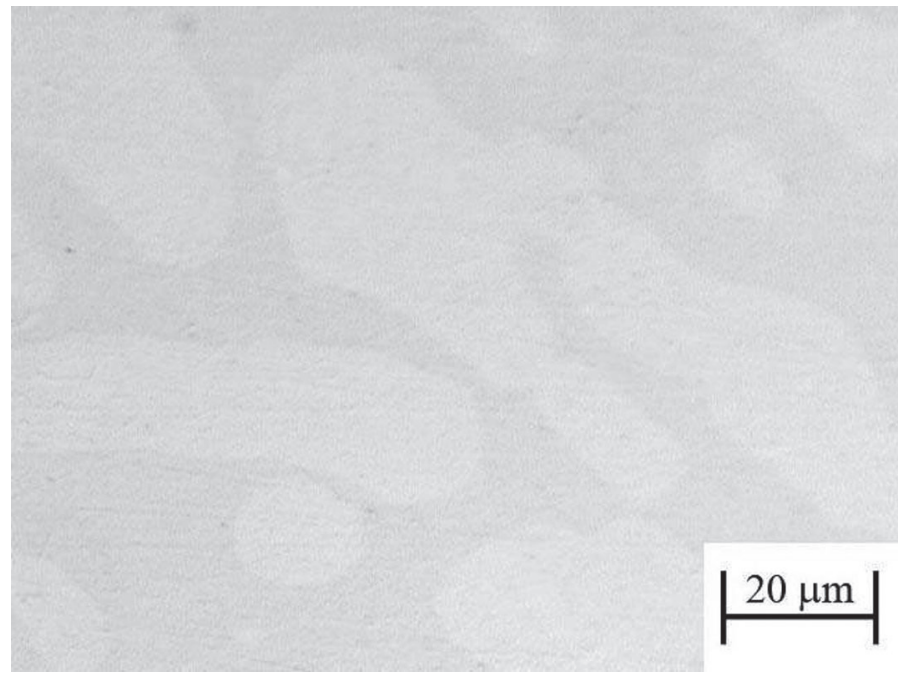

Figura 11. Microestrutura do MB atacada por $\mathrm{KOH}$ modificado.

A composição adotada para o reagente de $\mathrm{KOH}$ é mais fraca do que aquelas utilizadas em trabalhos prévios para materiais trabalhados e tratados termicamente de AISD [9]. A aplicação do reagente de $\mathrm{KOH}$ convencional para AID contendo $10 \mathrm{~g}$ de $\mathrm{KOH}$ para $100 \mathrm{ml}$ de água destilada resultou em um super ataque dos metais de solda analisados. Este fato pode ser atribuído à microestrutura mais fina existente no MS. Por esse motivo, optou-se pela utilização do reagente contendo $5 \mathrm{~g}$ de $\mathrm{KOH}$ para $100 \mathrm{ml}$ de água destilada, de modo a avaliar comparativamente os locais preferenciais de ataque se comparado com o MB da Figura 11.

Conforme observado, na Figura 12 do MS da raiz (GMAW - RAIZ 1), se exibem regiões suscetíveis de serem atacadas pelo reagente aplicado podendo corresponder a fases deletérias tais como chi $(\chi)$ e sigma $(\sigma)$ em estágios iniciais de precipitação. No entanto, este fato deve ser confirmado mediante o uso do MEV a ser realizado nestas amostras no modo de elétrons retroespalhados $(B S E)$ em amostras sem ataque prévio [9].

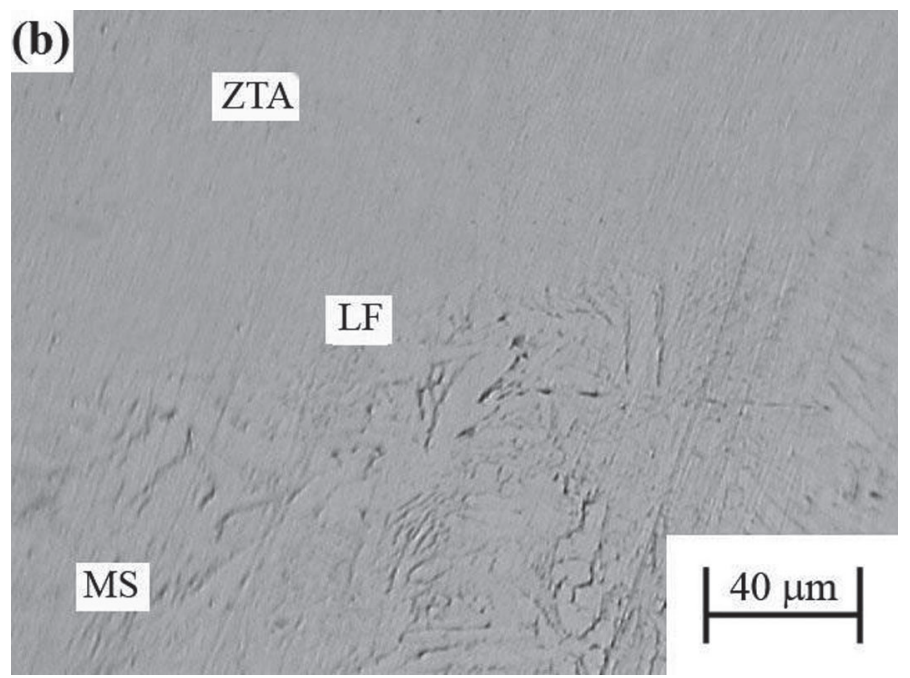

Figura 12. Microestrutura do GMAW - RAIZ 1 atacada por KOH e Microestrutura da LF do GMAW - RAIZ 1. 
A Figura 13 mostra a superfície de fratura do centro do metal de solda na raiz (CSR FRAT), onde os descontinuidades geradas pelo ensaio de impacto se concentraram preponderantemente na região ferrítica. Este fenômeno pode ser atribuído às fases deletérias precipitadas, pois é na fase ferrítica que estas fases, tal como sigma e chi, precipitam.

A Figura 14 (a) exibe a micrografia pela aplicação do reagente $\mathrm{KOH}$ da superfície lateral do cp Charpy no CSR (CSR FRAT LAT). Esta figura apresenta a mesma característica que a Figura 12, onde as regiões mais escuras podem corresponder a fases deletérias precipitadas. Destaca-se ainda, que nesta região se denotam mais claramente as fases precipitadas nas ferritas de menor tamanho.

A Figura 14 (b) mostra a superfície lateral da fratura (CSR FRAT LAT) na região da raiz atacada por $\mathrm{KOH}$ e por Beraha de forma sucessiva. Nela é possível visualizar a presença preferencial de descontinuidades na fase ferrítica. A presença destas descontinuidades pode ter sido originada pelas solicitações mecânicas do ensaio de impacto, mas destaca-se, como no caso da Figura 13, que as fases deletérias possam estar auxiliando na propagação das mesmas.

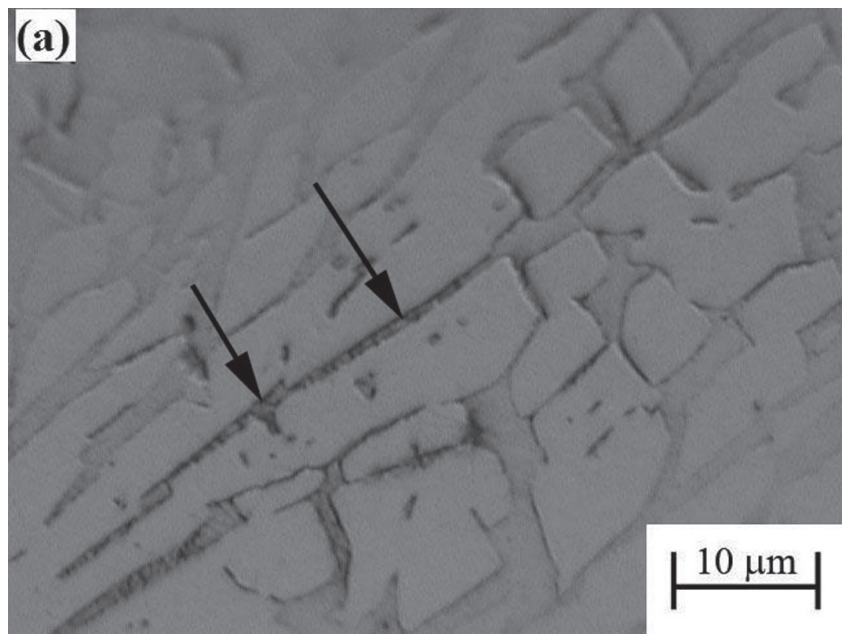

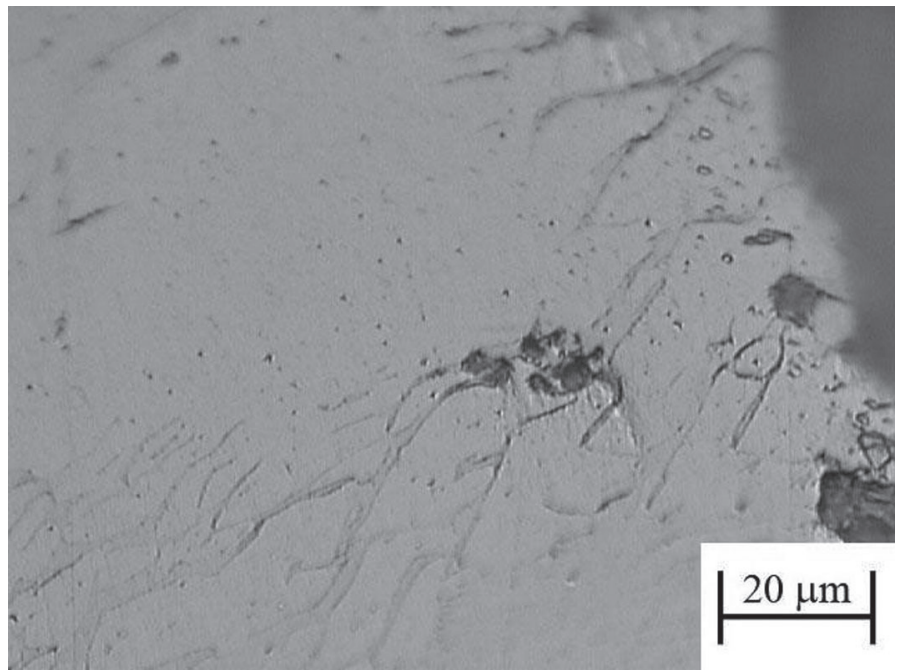

Figura 13. Microestrutura do CSR FRAT atacada por $\mathrm{KOH}$.

Já na Figura 15 (a) observa-se dentro das circunferências a presença de formação de $\mathrm{Cr}_{2} \mathrm{~N}$ na ferrita ao passo que na Figura 15 (b) observa-se a superfície de fratura (CSR FRAT) onde

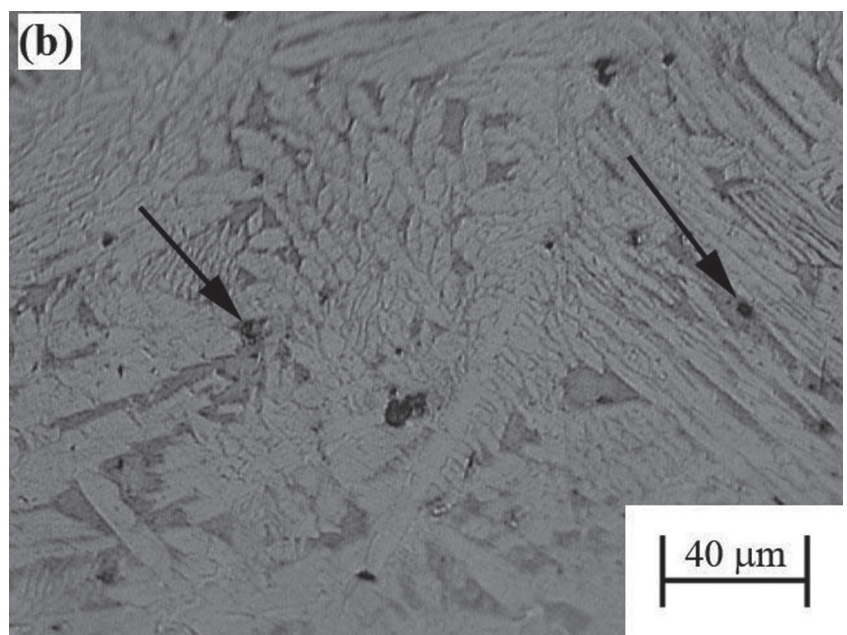

Figura 14. Microestrutura do CSR FRAT LAT. (a) atacada por KOH. (b) atacada sucessivamente por KOH e Beraha.
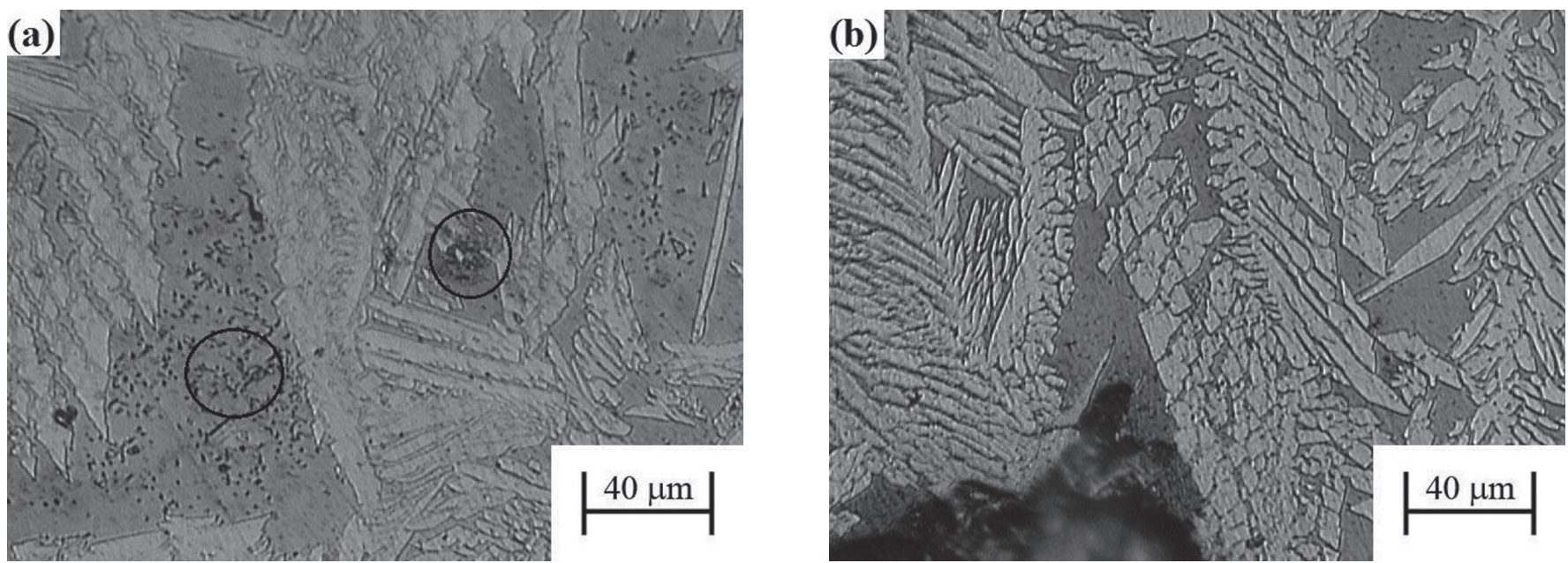

Figura 15. Microestrutura do CSR FRAT atacada por KOH e Beraha. 
as descontinuidades se encontram, preferencialmente, na fase ferrítica [4].

A Figura 16 mostra os valores de tenacidade ao impacto levantados ao longo da junta, na raiz e no enchimento, para as distâncias em relação ao centro de solda LF, LF+ $2 \mathrm{~mm}$ e LF+ $5 \mathrm{~mm}$. Através da análise desta figura é possível concluir que quanto mais próximo do centro de solda menor é a tenacidade. No entanto, todos os valores na região da raiz (R) foram inferiores ao da região do enchimento (S). Este fato pode ser atribuído à influência dos sucessivos ciclos térmicos e das altas temperaturas de interpasse na soldagem de modo que possam ter promovido, fundamentalmente no centro do metal de solda da raiz, uma probabilidade maior de fragilização por presença incipiente de fases deletérias. Este fato está de acordo com as micrografias reveladas pelo reagente de $\mathrm{KOH}$. No presente projeto, as altas temperaturas de interpasse causaram na região no centro de solda da raiz uma tenacidade média abaixo de 27J à temperatura de $-46^{\circ} \mathrm{C}$, se encontrando levemente abaixo do limite mínimo estipulado pela norma NORSOK M-601 [3].

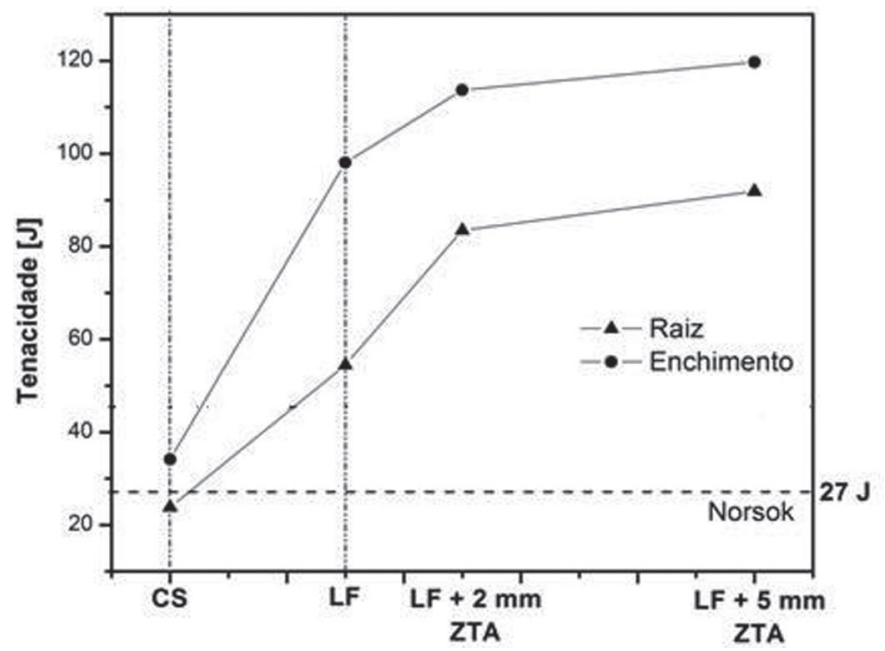

Figura 16. Tenacidade ao longo da junta na raiz $(\mathrm{R})$ e no enchimento $(\mathrm{E})$.

Os valores das temperaturas críticas de pites $(C P T)$ encontrados para as condições $S A W$ - ZTA MB, GMAW - RAIZ 1, GMAW - RAIZ 2, SAW - ENCH. CENTRAL e MB são apresentados na Tabela 7 .

Tabela 7. Resultados dos ensaios de temperatura crítica de pites.

\begin{tabular}{|c|c|c|c|c|}
\hline \multirow[b]{2}{*}{ Localização } & \multicolumn{4}{|c|}{$C P T\left({ }^{\circ} \mathrm{C}\right)$} \\
\hline & $\begin{array}{c}1^{\circ} \\
\text { Ensaio }\end{array}$ & $\begin{array}{c}2^{\circ} \\
\text { Ensaio }\end{array}$ & $\begin{array}{c}3^{\circ} \\
\text { Ensaio }\end{array}$ & Média \\
\hline$G M A W-$ RAIZ 1 & 37,04 & 42,65 & 39,61 & $39,77 \pm 2,81$ \\
\hline$G M A W-$ RAIZ 2 & 45,70 & 54,39 & 49,30 & $49,80 \pm 4,37$ \\
\hline $\begin{array}{l}\text { SAW ENCH. - } \\
\text { CENTRAL }\end{array}$ & 52,87 & 52,40 & 49,79 & $51,69 \pm 1,66$ \\
\hline$S A W$ - ZTA MB & 41,80 & 36,20 & 35,01 & $37,67 \pm 3,63$ \\
\hline MB & 53,90 & 57,00 & 49,30 & $53,40 \pm 3,87$ \\
\hline
\end{tabular}

Comparando-se a $C P T$ entre o MB e a GMAW - RAIZ 1, na Tabela 7, observa-se que a $C P T$ na raiz é bem menor em função da influência dos passes de solda com temperaturas de interpasse elevadas, sendo mais susceptível à corrosão. Destacase também, que a ZTA da amostra (SAW - ZTA MB), extraída entre as camadas 5 e 6 , teve um valor médio de $C P T$ comparável à da raiz, em função da temperatura interpasse atingir valores de aproximadamente $290^{\circ} \mathrm{C}$.

A Tabela 8 exibe o teor de nitrogênio $(\mathrm{N})$ medido pelo método de combustão, destacando-se que a raiz possui um teor $31 \%$ inferior ao do metal de base, indicando que houve uma perda deste elemento em virtude dos sucessivos reaquecimentos.

Tabela 8. Resultados obtidos do nitrogênio contido na liga (\% em peso).

\begin{tabular}{|c|c|}
\hline Região da Junta & N (\%) \\
\hline $\boldsymbol{G M} \boldsymbol{A} \boldsymbol{W}-$ Raiz & 0,097 \\
\hline $\boldsymbol{S} \boldsymbol{A} \boldsymbol{W}$ - Enchimento & 0,130 \\
\hline $\boldsymbol{S} \boldsymbol{W}-$ Acabamento & 0,117 \\
\hline $\boldsymbol{S A} \boldsymbol{W}-$ MB & 0,141 \\
\hline
\end{tabular}

\section{Conclusões}

O presente trabalho permite concluir, para a condição de soldagem do AID estudado, que:

- A influência dos sucessivos ciclos térmicos, considerando uma elevada temperatura interpasse, não afetou significativamente a proporção de fases na região da raiz da solda.

- Foi aplicado com sucesso o reagente KOH modificado, possibilitando distinguir a presença provável, em estágios iniciais de precipitação, de fases deletérias, principalmente na raiz do MS.

- Os valores de tenacidade ao impacto são inferiores quanto mais próximo do centro da solda estiver o entalhe. Na raiz os valores foram inferiores aos da região do enchimento atribuído à influência dos sucessivos ciclos térmicos e das altas temperaturas de interpasse na soldagem.

- O valor da $C P T$ na raiz (GMAW - RAIZ 1) é bem menor ao MB em função da influência dos passes de solda com temperaturas de interpasse elevadas, sendo mais susceptível à corrosão. A condição $S A W$ - ZTA MB teve um valor médio de $C P T$ comparável à da raiz em função da temperatura interpasse atingir valores de aproximadamente $290^{\circ} \mathrm{C}$.

- $\mathrm{O}$ teor de nitrogênio medido na raiz possui um teor $31 \%$ inferior ao do metal de base indicando que houve uma perda deste elemento em virtude dos sucessivos reaquecimentos.

- Finalmente, pode-se concluir que o emprego de temperaturas interpasses entre 150 e $290^{\circ} \mathrm{C}$ na soldagem teve como conseqüência, na região da raiz do centro da solda, valores médios de tenacidade de $23,81 \mathrm{~J}$ encontrando-se abaixo daquele permitido pela norma. Esse fato também refletiu na $C P T$ da raiz da solda, sendo este parâmetro de importância nesta região, pois é ela que fica em contacto com o fluido de processo que circula pela tubulação. 


\section{Agradecimentos}

À UTC Engenharia pelo grande suporte na realização deste trabalho.

À APERAM pelas análises do teor de nitrogênio.

À CAPES, à FAPERJ e ao CNPq pelo suporte financeiro na realização deste trabalho..

\section{Referências Bibliográficas}

[1] GUNN, R.N. "Duplex stainless steels. Microstructure, properties and applications". Cambridge - England: Abington Publishing, 2003. 204 p.

[2] REICK, W.; POHL, M.; PADILHA, A.F. “O desenvolvimento dos aços inoxidáveis ferríticos-austeníticos com microestrutura duplex". In: CONGRESSO ANUAL DA ABM, 47. 1992, Belo Horizonte. Anais: ABM, 1992. Vol 48, No409.

[3] NORSOK STANDARD M-601: "Welding and Inspection of Piping”. Rev. 4, July 2004.

[4] PARDAL, J.M., SOUZA, G.C., TAVARES, S.S.M., CINDRA FONSECA, M.P., FERREIRA, M.L.R., MARTINS, L.M., SAMRA FILHO, O.A. "Caracterização e Avaliação da Resistência à Corrosão na Soldagem de Tubulação de Aço Inoxidável Duplex UNS S31803 pelo Processo a Arco Submerso". Soldagem e Inspeção. 2011; Vol. 16 N²4: 310-321.

[5] IMOA - INTERNATIONAL MOLYBDENIUM ASSOCIATION. "Practical guidelines for the fabrication of duplex stainless steels". London - England, 2009. 63 p. Disponível em:< http://www.imoa.info/_files/stainless_steel/ Duplex_Stainless_Steel_2d_Edition.pdf $>$. Acesso em: 10 Out. 2012.

[6] ASME B31.3. "Process Piping". 2008, Edition.

[7] ASTM E 23-05: "Standard Test Methods for Notched Bar Impact Testing of Metallic Materials".

[8] SBM SPF92033A1: "Fabrication, Welding and Erection Specification".

[9] PARDAL, J.M., TAVARES, S.S.M., CINDRA FONSECA, M.P., SOUZA, J.A., VIEIRA, L.M., ABREU, H.F.G. "Deleterious Phases Precipitation on Superduplex Stainless Steel UNS S32750: Characterization by Light Optical and Scanning Electron Microscopy". Materials Research. 2010; Vol. $13 \mathrm{~N}^{\circ} 3$ : 401-407.

[10] IMAGE TOOL Version 3.0. Department of Dental Diagnostic Science at The University of Texas Health Science Center (UTHSCSA), San Antonio, Texas. Disponível em: < http://compdent.uthscsa.edu/dig/itdesc.html >. Acesso em: 10 Out. 2012.

[11]ASTM G150-99: "Standard Test Method for Electrochemical Critical Pitting Temperature Testing of Stainless Steels". 